\title{
The smart transition of Power Transmission Network needed for the sustainable development of Bucharest City
}

\author{
Mircea Scripcariu ${ }^{1 *}$, Cristian Gheorghiu ${ }^{2}$, Ion Tristiu ${ }^{3}$ and Alexandra-Gabriela Dobrica ${ }^{4}$ \\ ${ }^{1}$ Associate Prof., Dept. of Energy Production and Use, University POLITEHNICA of Bucharest, \\ Romania \\ ${ }^{2} \mathrm{PhD}$. Student, Dept. of Energy Production and Use, University POLITEHNICA of Bucharest, \\ Romania \\ ${ }^{3}$ Professor, Dept. of Power Systems, University POLITEHNICA of Bucharest, Romania \\ ${ }^{4}$ Master Degree Student, Dept. of Energy Production and Use, University POLITEHNICA of \\ Bucharest, Romania
}

\begin{abstract}
Large cities around the world continue to grow larger. This is also the case of Bucharest, the capital city of Romania and one of the largest and most densely populated locations in Eastern Europe. In this article authors present an overview of the development of Bucharest as the largest electricity consumer amongst the Romanian municipalities and analyse possible solutions for the refurbishment of the HV (High Voltage) grid. This process needs to help the city development and its transition to a Smart City. At first authors present the strategy of local authorities for improving the living standard and decrease the environmental pollution. The impact of this strategy on the electrical energy demand is further analysed. Possible technologies are presented for substations and electrical lines starting from the current situation of the transmission network. All these can contribute to a decrease of the environmental impact and to an increase in the continuity of the power supply. Technical and economical evaluation of the refurbished grid is further presented along with a sensitivity analysis. The evaluation of the investment is made by taking into consideration the demand forecast. Lines and transformers are sized and chosen with the best available technology. For the economic analysis authors used criteria accepted by funding sources, banks especially, such as NPV and IRR. The sensitivity of the project economics is tested and discussed. As conclusions authors present the environmental benefits of gradually changing the technology used for electricity transmission in a large city such as Bucharest, mainly regarding land occupancy with switchgear and line routes and soil pollution.
\end{abstract}

\footnotetext{
"Corresponding author : mirceas1960@yahoo.com
} 


\section{Bucharest's road map towards a Smart City}

In the last decades cities around the world embraced the smart development concept [1]. In 2008 , the $50 \%$ threshold of persons living in cities was broken [2]. Furthermore, the United Nations Population Fund-UNFPA foresees that urban population will represent $70 \%$ of the total in 2050 [2].

By 2011, in EU-28 were living 503 million inhabitants [3], of which $42.4 \%$ in a predominantly urban region, $35.3 \%$ in an intermediate region and $22.3 \%$ in a predominantly rural region [4]. According to the definition, the predominantly urban regions have less than $20 \%$ rural population, intermediate regions between $20 \%$ and $50 \%$ and predominantly rural regions more than $50 \%$ [5]. Compared to 2006, the growth of the population in the predominantly urban region is of $1.1 \%$ in the detriment of predominantly rural region [5]. At the beginning of 2020, EU-28 had 503 million inhabitants [3], rising with over $2 \%$ compared to 2011 . In 2013, the world's urban areas accounted for about $64 \%$ of global primary energy use and produced $70 \%$ of the planet's carbon dioxide emissions [6].

Cities around the world are developing strategies and master plans on the road to decarbonization. In the USA, small communities are already running entirely on renewable power, including Aspen, Colorado, and Burlington, Vermont [6]. "Bigger cities have set ambitious goals, with Copenhagen, Denmark, aiming to be carbon neutral by 2025. San Diego, California, aims to be $100 \%$ powered by renewable sources by 2035 , and Vancouver, Canada, by 2050" [6]. There is a remarkable trend for sustainability and cities are taking actions like joining in larger organizations with clear targets to tackle the climate change. C40 Cities Climate Leadership Group was established as a global network of cities that are developing and implementing policies to reduce emissions [6].

The European Environment Agency states that "Europe currently does not live up to its 2050 vision of 'living within the limits of our planet'. This calls for fundamental changes in lifestyles, production and consumption, knowledge and education" [7].

According to data from the National Institute of Statistics [8], Bucharest has 2.13 million inhabitants in 2019 from 2.11 million in 2015. The population growth is not spectacular, but as capital city of Romania it became a crowded area. According to Forbes, Bucharest is the main driving force of economic growth in Romania, generating $20 \%$ of the GDP. In a chart provided by Easy Park Group [9], Bucharest is ranked on the $87^{\text {th }}$ position among 500 cities considered in a study from 2017, that took into consideration factors such as: Transportation and mobility, Sustainability, Administration, Business environment, Digitalization, Living standard, Experts perception regarding city development.

IMD WORLD COMPETITIVENESS CENTER ranks Bucharest on the $85^{\text {th }}$ position in another smart city index. Any smart strategy brings cities economic growth and social benefits. For example, in Copenhagen, Denmark, business opportunities of over Euro 100 million were generated in 2015 [10].

To channel a large municipality such as Bucharest towards a smart city there is a need for continuous transformation of three essential pillars, the administration, the technology and the society. A smart Bucharest will be the result of the cumulated effort of local administration and public authorities, private businesses, telecoms, utilities, building owners associations, transportation companies, health organizations and education organizations (schools, universities etc.) and finally, of each citizen. The energy infrastructure in Bucharest is well developed but obsolete. The district heating system is inefficient and in poor financial situation. The electricity transmission and distribution systems are using old technologies, influencing the sustainability and the living standard. They occupy land with large substations and overhead lines and by using equipment with oil, create a hazard for soil and underground water. 
Data from the residential market show that in Bucharest around 10,000 new apartments are commissioned each year. Most of these are part of residential areas developed in the outskirts of the city where there are high voltage substations and overhead lines. These are imposing restrictions to real estate developments. Along with residential developments, malls are erected. All these represent new electricity consumers that put pressure on the modernization of the electricity transmission and distribution infrastructure. The Sustainable Urban Mobility Plan shows, in the optimal scenario, that the metro system will be extended with two new mains (M5 and M6) and M2 and M3 will be lengthened [11]. New fast tramways lines are in this plan, too. One is under construction for the 2021 European Football Championship. The mobility plan shows that electrically driven systems will be developed with priority, adding on the pressure for the modernization of the electricity network. The Municipality is investing in around 300 charging stations for EVs.

Next, the authors will analyse only the smart initiatives in Bucharest city with impact on the electricity network. In section 2 authors analyse the impact of smart initiatives, of population growth and of economic development on the electricity demand forecast. Section 3 is dedicated to the presentation of the current situation of the transmission grid supplying the city of Bucharest and of the associated environmental impact. In section 4, authors present the technological solutions for the refurbishment of the transmission grid that are technically and economically analysed in section 5 . The conclusions of the current research and further initiatives are presented in section 6 .

\section{Demand Forecast}

The continuous growth in the number of inhabitants, the economic development, the development of the electrically driven public transportation and the evolution of EV market will lead the electricity demand to higher levels. Electricity networks in Bucharest need to be resized and gradually replaced to match this growth. According to E-Distributie Muntenia Sud, the electricity distribution company operating in Bucharest, the peak load was in the last years over 1,000 MW and is steadily growing. The power transmission system operator, CNTEE Transelectrica, following data from the National Commission for Strategy and Prognosis, is forecasting an electrical energy consumption growth with a yearly rate of about $1.1 \%$ [12]. The peak load demand will follow the same pattern. According to [12], 15\% of the national electricity consumption is represented by Bucharest. Consequently, the electricity forecast for Bucharest is presented in Table 1.

Table 1. The annual energy consumption and the peak demand forecast for the City of Bucharest [12]

\begin{tabular}{|c|c|c|c|c|c|c|c|}
\hline YEAR & 2021 & 2022 & 2023 & 2024 & 2025 & 2026 & 2027 \\
\hline Wy [TWh/year] & 8,625 & 8,700 & 8,790 & 8,895 & 8,985 & 9,075 & 9,165 \\
\hline Ppeak [MW] & 1,362 & 1,378 & 1,394 & 1,410 & 1,425 & 1,440 & 1,454 \\
\hline
\end{tabular}

The total installed capacity in (auto)transformers in the three substations supplying Bucharest is 1,900 MVA and the "n-1" criterion is not fulfilled at peak load. Beyond 2027 is expected a sharp increase in the transition from fossil fuel transportation to full-electric and hybrid. Combined with the increase in the demand of the public transportation, an increase over $10 \mathrm{TWh}$ of the energy consumption can be expected beyond 2030. This forecast shows that the power transmission network needs investments in modernization and strengthening. The power growth will be ensured by wind developments in Dobrogea region (south-eastern part of Romania) and the expected development with two new nuclear units of Nuclear Power Plant (NPP) Cernavoda. 


\section{Current Situation of the Power Transmission Grid and it's main Environmental Impact}

The city of Bucharest is supplied through two $400 \mathrm{kV}$ substations, Domnesti and Bucharest South, and a $220 \mathrm{kV}$ substation, Fundeni. In Table 2 the loading of the power transformers in each substation at the Winter Peak Load (WPL) is presented. Substation Domnesti is equipped with transformers (T) and substations Bucharest South and Fundeni are equipped with autotransformers (AT).

Table 2. Loading Factor of the Power Transformers installed in the substations supplying Bucharest City, WPL, 2017 [13]

\begin{tabular}{|c|c|c|c|c|c|}
\hline $\begin{array}{c}\text { Equipment } \\
\text { T/AT }\end{array}$ & Substation & Voltage ratio & $\begin{array}{c}\text { Rated power } \\
\left(\mathbf{S}_{\mathbf{n}}\right)\end{array}$ & $\begin{array}{c}\text { WPL 2017 } \\
(\mathbf{S})\end{array}$ & $\begin{array}{c}\text { Load Factor } \\
\text { S/. }\end{array}$ \\
\hline- & - & - & MVA & MVA & $\%$ \\
\hline AT3 & Bucharest South & $400 / 220 / 20$ & 400 & 288.4 & 72.10 \\
\hline AT4 & Bucharest South & $400 / 220 / 20$ & 400 & 288.4 & 72.10 \\
\hline T1 & Domnesti & $400 / 110$ & 250 & 109.2 & 43.68 \\
\hline T2 & Domnesti & $400 / 110$ & 250 & 98.2 & 39.28 \\
\hline AT1 & Fundeni & $220 / 110$ & 400 & 193.42 & 48.36 \\
\hline AT2 & Fundeni & $220 / 110$ & 400 & 189.67 & 47.42 \\
\hline
\end{tabular}

Data in table 2 confirm that Bucharest South substation needs capacity strengthening. Domnesti and Fundeni substations are at the limit if considering the "n-1" criterion. The Overhead Lines (OHL) connecting these substations are loaded at over $60 \%$ of their thermal capacity. The main environmental impacts of OHLs and substations in the operation stage are: Land occupancy, Visual impact, Noise, mainly determined by the Corona phenomenon, Deforestation and Soil pollution with mineral oil and chemical substances. In the decommissioning stage, the environmental impact is determined by the huge amount of materials resulting, that need to be recycled, reused or stored.

In table 3, the typical amount of materials that result when a substation with classic Air-Insulated Switchgear (AIS) is decommissioned, is presented. Electrical apparatuses are oil insulated type and the circuit-breakers have oil for arch extinction. The example is given for a 400/220/110 kV substation with a total of 44 circuits and a Double Busbar System with a Bypass Busbar (2BB+BB) Single Line Diagram (SLD). The total oil quantity does not include auto (transformers). This data was calculated as part of a study prepared for the transmission grid operator [14]. Bucharest South substation has the same SLD (Single Line Diagram), a similar number of circuits and the same technology for the switchgear. So, when decommissioned one can expect to result the same amount of different materials.

Table 3. Typical amount of materials resulted when a substation with classic AIS (44 circuits) is decommissioned [14]

\begin{tabular}{|c|c|c|c|c|c|c|c|}
\hline $\begin{array}{c}\text { Rated } \\
\text { Voltage }\end{array}$ & SLD & $\begin{array}{c}\text { Mineral } \\
\text { Oil }\end{array}$ & $\mathbf{A} \mathbf{I}^{*}$ & $\begin{array}{c}\text { Support insulators } \\
\text { and extinction } \\
\text { chambers }\end{array}$ & Concrete & Steel & Other \\
\hline $\mathbf{k V}$ & - & kg & kg & kg & $\mathbf{m}^{3}$ & kg & kg \\
\hline 110 & \multirow{3}{*}{$2 \mathrm{BB}+\mathrm{BB}$} & \multirow{3}{*}{139,000} & \multirow{3}{*}{89,000} & \multirow{3}{*}{$1,400,000$} & \multirow{3}{*}{2,400} & \multirow{3}{*}{14,500} & \multirow{3}{*}{185,000} \\
\hline 220 & & & & & & & \\
\hline 400 & & & & & & & \\
\hline
\end{tabular}

* Aluminium resulting only from disconnecting-switch contacts and locking coils. 
When decommissioning a $400 \mathrm{kV}$ OHL, only form the insulation system may result $3,200 \mathrm{~kg} / \mathrm{km}$ of porcelain. From the protection wire alone may result $500 \mathrm{~kg} / \mathrm{km}$ of aluminium and $700 \mathrm{~kg} / \mathrm{km}$ of steel. Regarding the land occupancy, substations with AIS technology occupy important surfaces, see table 4 .

Table 4. Land occupancy by the substations supplying the City of Bucharest [15]

\begin{tabular}{|c|c|c|}
\hline Substation & Rated Voltage & Surface \\
\hline- & $\mathbf{k V}$ & $\mathbf{m}^{\mathbf{2}}$ \\
\hline Domnesti & $400 / 110$ & 56,687 \\
\hline Bucharest South & $400 / 220 / 110$ & 89,155 \\
\hline Fundeni & $220 / 110$ & 59,534 \\
\hline
\end{tabular}

The OHLs linking the three substations supplying Bucharest city need important surfaces for their routes (see table 5). The land is occupied for the entire normal operation duration of the line only by the posts. For overhead lines this duration is between 32-48 years. The OHLs crossing Bucharest exceed this operation interval.

Table 5. Routes dimensions for the OHLs connecting the substations supplying the city of Bucharest [12]

\begin{tabular}{|c|c|c|c|c|}
\hline OHL & Rated Voltage & Length & Route width* & Route Surface \\
\hline- & $\mathbf{k V}$ & $\mathbf{k m}$ & $\mathbf{m}$ & $\mathbf{m}^{\mathbf{2}}$ \\
\hline $\begin{array}{c}\text { Bucharest South }- \\
\text { Domnesti }\end{array}$ & 400 & 34.367 & 75 & $2,577.525$ \\
\hline $\begin{array}{c}\text { Bucharest South }- \\
\text { Fundeni }\end{array}$ & 220 & 25.030 & 55 & $1,376.650$ \\
\hline
\end{tabular}

* as per the technical norm NTE 003 for the construction of OHLs with a rated voltage of over $1,000 \mathrm{~V}$ [16].

According to [16], possible crossing of lines over inhabited or not inhabited buildings should be avoided as much as possible. The crossing can be accepted only with the approval of the transmission system operator and if the material of the roof is fire resistant, and if it is from metal needs to be connected to an earthing installation. The installation of posts in the proximity of intensive pedestrian-traffic areas should be avoided (such as the entrance of a building). In fig. 1 we present the situation when a post foundation for one of the above-mentioned lines is within the perimeter of two inhabited buildings. We presume that these buildings were erected after the line commissioning and are part of the development of the urban area of the city of Bucharest. Their construction may not respect the provisions of the technical norms.

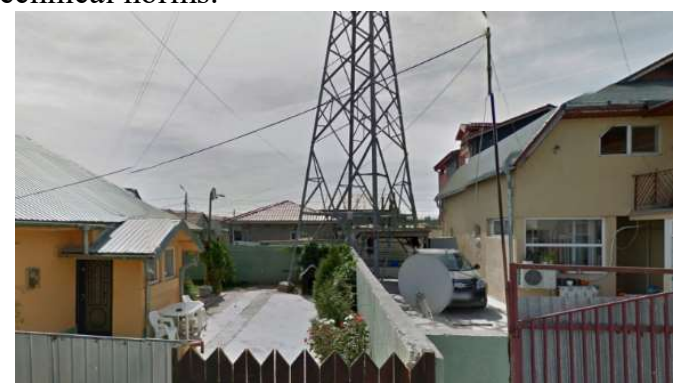

Fig. 1. OHL post with foundation within the premises of an inhabited building

The transmission network supplying with electricity the capital city of Romania has a major environmental impact by occupying the land with substations and line routes, by 
representing a potential threat to the soil by means of oil pollution, by generating sound pollution due to the Corona effect and by having a negative visual impact.

\section{The solution for improving the environmental impact and the electrical capacity of the Power Transmission Network}

From the '60, electrical installation manufacturers made a technological breakthrough by using $\mathrm{SF}_{6}$ (Sulphur hexafluoride) in circuit-breakers. The use of this gas was extended as an insulator between phases in a GIS (Gas Insulated Switchgear) installation for substations. The greatest advantage being the small surfaces occupied by substations. In Table 6 we present, for a typical bay, the approx. dimensions for AIS (Air Insulated Switchgear) and GIS technologies.

Table 6. Main Constructive features of AIS and GIS bays [12]

\begin{tabular}{|c|c|c|c|c|c|c|c|}
\hline $\begin{array}{c}\text { Rated Voltage } \\
{[\mathbf{k V}]}\end{array}$ & Technology & Bay Type & SLD & $\begin{array}{c}\text { Length } \\
{[\mathbf{m}]}\end{array}$ & $\begin{array}{c}\text { Width } \\
{[\mathbf{m}]}\end{array}$ & $\begin{array}{c}\text { Surface } \\
{\left[\mathbf{m}^{2}\right]}\end{array}$ & $\begin{array}{c}\text { Surface } \\
\text { ratio } \\
(\mathbf{A I S} / \mathbf{G I S})\end{array}$ \\
\hline $220^{*}$ & AIS & OHL & 2BB & 71.00 & 17.0 & $1,207.00$ & - \\
\hline 220 & AIS & OHL-AT** & 2BB + BB & 171.10 & 17.0 & $2,908.70$ & - \\
\hline $220^{*}$ & GIS & line & 2BB & 5.00 & 1.6 & 8.00 & 151 \\
\hline $400^{*}$ & AIS & OHL & 2BB & 89.90 & 22.5 & $2,022.75$ & - \\
\hline 400 & AIS & OHL-T*** & 2BB + BB & 209.80 & 22.5 & $4,720.50$ & \\
\hline $400^{*}$ & GIS & line & 2BB & 7.715 & 2.25 & 17.36 & 117 \\
\hline
\end{tabular}

* Selected for calculating the surface ratio (AIS/GIS),

** OHL and autotransformer (AT) bays over the same bay pitch, face to face arrangement, *** OHL and transformer (T) bays over the same bay pitch, face to face arrangement.

$\mathrm{SF}_{6}$ is raising concerns because it is a greenhouse gas with a contribution 23,500 times more than $\mathrm{CO}_{2}$. For that, manufacturers guarantee high levels of safety against leakages and, at the same time, are investing in research to find a better gas from an environmental impact point of view. In the last years, large manufacturers announced the trial of GIS installations using gases with no environmental impact. At the same time keeping the same advantages regarding the surfaces needed for single bays [17 - 19].

For the connections between the substations of the transmission network supplying Bucharest, the only proven technology available is the use of high voltage cables to replace the existing OHLs. One of the most widespread technologies for high voltage cable manufacturing is to use cross-linked polyethylene (XLPE) for insulation. The conductor may be of aluminium or copper. The main advantages of these cables are flexibility, reduced weight, resistance to environmental impact and low operation costs. The mounting solution can be buried or posed in ducts. The last solution has the advantages of fast access for maintenance and increased mechanical protection. The technical and economical evaluations were done for a solution using XLPE cables posed in ducts. This mounting solution can provide also the opportunity to pose optical fibre, much needed for the development of a smart Bucharest. Choosing the optimal posing and layout of the high voltage cables should result from an in-depth study regarding the electromagnetic compatibility and the operation and maintenance procedures.

The strategy for the evolution towards a smart city for Bucharest is requesting the development and refurbishment of the transmission network. The technologies that authors consider to be the most appropriate for fulfilling this target are the use of GIS installations in all transmission substations and the use of cables for the connection between substations. The power demand forecast presented in section 2 and the load factor for the power transformers presented in section 3 were taken into consideration for the proposed profile of equipping the refurbished network with transformers. Hence, it's been proposed to replace 
the existing power transformers located in Bucharest South Substation with larger ones, with a rated power of 630 MVA.

The refurbishment and development of the power transmission network in Bucharest city has a number of main objectives: Reducing the visual impact and the soil pollution caused by the old technology, Increasing the power grid capacity in order to support the continuous economic development and the transition to electric transportation (EVs, the development of the underground metro network etc.). CNTEE Transelectrica SA planned measures for the development of the network, like a new substation in the centre of the city, in Grozavesti area, as a medium term measure and the development of another substation, in the eastern part of the city, but close to the city centre, as a long-term measure [12]. Both substations will be linked with cables to the existing network. These projects are very uncertain due to land issues and were not considered in our analysis.

\section{The Technical and Economic Analysis of the Refurbishment Solution for the Power Transmission Network supplying the city of Bucharest}

The main hypothesis for the technical calculation, were to consider that the same generation capacities exist in the power plants in Bucharest. There are no new generation units forecasted. In the power transmission network, as a node, the Brazi West substation was also included. In the first stage of the analysis the maximum three phase short-circuits currents in the main substations was calculated, in order to establish if there are any restrictions regarding the switchgear characteristics, determined by the introduction of cables, that have a specific reactance lower than that for OHLs. In table 7 the results of the calculations for the existing situation and for the proposed refurbishment are shown. The symmetrical component method [21] was used to determine the maximum three-phase short-circuit current in both the actual and the proposed scenarios, by using an equivalentgenerator. The most important increase in the short-circuit current was identified in the 400 $\mathrm{kV}$ nodes. This value is lower than the values given for the rated breaking current by all the major GIS manufacturers. The refurbishment process needs to be planned so that the increase of currents in the fault state is carefully managed. This is caused by the introduction of cables but also by the increase in the T/AT rated power to match the conditions of the steady state.

Table 7. Three phase short-circuit current in the Power Transmission Network's nodes

\begin{tabular}{|c|c|c|c|}
\hline Substation & $\begin{array}{c}\text { Rated } \\
\text { Voltage } \\
{[\mathbf{k V}]}\end{array}$ & $\begin{array}{c}\text { Actual three phase short- } \\
\text { circuit current intensity } \\
{[\mathbf{k A}]}\end{array}$ & $\begin{array}{c}\text { Forecasted three phase short- } \\
\text { circuit current intensity } \\
{[\mathbf{k A}]}\end{array}$ \\
\hline Bucharest South & 400 & 28.21 & 37.07 \\
\hline Bucharest South & 220 & 23.74 & 24.91 \\
\hline Brazi West & 400 & 26.51 & 26.92 \\
\hline Domnesti & 400 & 28.85 & 37.43 \\
\hline
\end{tabular}

For the economic analysis were used the most accepted criterions by the main funding organizations, the Net Present Value - NPV (1), Internal Rate of Return - IRR (2) and the Simple Payback Period - SPP (3).

$$
N P V=\sum_{t=1}^{t_{s t}} \frac{I_{t}-C_{t}}{(1+a)^{t}}-I C[E U R]
$$

where $t_{s t}$ is the analysis time-frame, in years, $I_{t}$ is the yearly income in the $\mathrm{t}^{\text {th }}$ year, in EUR/year, $C_{t}$ are the yearly expenditures in the $\mathrm{t}^{\text {th }}$ year, in EUR/year, $a$ is the discount rate, in $\% /$ year. 


$$
N P V=\sum_{t=1}^{t_{s t}} \frac{I_{t}-C_{t}}{(1+I R R)^{t}}=0[E U R]
$$

where the Investment Cost can be included in the yearly expenditures as a depreciation cost.

$$
S P P=\frac{I C}{\frac{\sum_{i=1}^{t} I_{i}-C_{i}}{t}}[\text { years }]
$$

where $I C$ is the investment cost, in EUR.

Due to differences in the useful life of different components of the transmission network, an analysis period of 14 years, according to legal provisions, was considered [22]. The Romanian transmission operator is listed at the Bucharest stock exchange and it raises money for investments in different ways, form banks, from corporate bonds etc. [22]. Considering also the good practice in the energy sector, we used a discount rate of $10 \%$ year. With the investment cost authors took into consideration a complete refurbishment of the substations and a possible route for HV (High Voltage) cables. Because the operation of cables generates reactive power into the network, an investment in compensation coils was added. The length and routes of cables will be clarified at the feasibility study stage. For the calculation of the operational cost with energy and power losses, the electricity price was set at $50 \mathrm{EUR} / \mathrm{MWh}$. This value is an average price, because the transmission operator buys electricity from the spot market and from the market for bilateral contracts. For current operation, authors also considered a set of maintenance and repairing costs. The technology proposed for substations has lots of references worldwide. Transelectrica is operating GIS substations, like the 400/220 kV substation Brazi West, but no HV cable. Operation costs are significantly lower for GIS bays than for the present AIS bays. Because the continuity of the transmission service has had good indicators in the last years [12], [15], [20-23] the cost of interruptions is significantly lower than the other annual costs and was neglected.

The income is generated by the transmission activity at an average price of around 4 EUR/MWh. Because in Bucharest for the next years one can expect only a continuous increase in the electricity demand, see section 2 , the income will increase annually. The value in table 9 is obtained by considering the annual increase of income as a direct effect of the annual increase in energy demand. In Table 8 the main costs and income of such a refurbishment process are shown.

Table 8. Investment, Annual Revenues and Operation and Maintenance (O\&M) Costs of the Power Transmission Network Refurbishment

\begin{tabular}{|c|c|c|}
\hline Financial Entry & Value & M.U. \\
\hline Investment Costs $(I C)$ & $275,000,000$ & {$[$ EUR] } \\
\hline Annual Income $\left(I_{t}\right)$ & $42,600,000$ & {$[$ EUR/year] } \\
\hline Annual Cost of Power and Energy Losses $(\mathrm{CPW})$ & $6,900,000$ & {$[$ EUR/year] } \\
\hline Operation and Maintenance Costs $(\mathrm{O} \& \mathrm{M})$ & $1,200,000$ & {$[$ EUR/year] } \\
\hline
\end{tabular}

Table 9. Financial Indicators for the refurbishment project

\begin{tabular}{|c|c|c|}
\hline Financial Indicator & Value & M.U. \\
\hline NPV & 100,000 & {$[$ EUR] } \\
\hline IRR & 10.1 & {$[\% /$ year $]$} \\
\hline SPP & 6.5 & {$[$ years] } \\
\hline
\end{tabular}

For the technology proposed for cables and substations, the operation and maintenance costs are very low compared to the existing ones. In order to obtain attractive results for the technical and economic analysis, the Transport System Operator (TSO) should raise the 
transport tariff from $4 \mathrm{EUR} / \mathrm{MWh}$ to $4,2 \mathrm{EUR} / \mathrm{MWh}$ - a $8 \%$ increase, which is justifiable considering the high amount of capital invested in this project. With all these costs considered, the results of the economic analysis are presented in table 9.

The results presented in Table 9 show that the project becomes viable if the analysis period is at least 14 years, as the NPV is close to 0 and the IRR is close to the Discount Rate. Considering the average lifetime of the equipment available on the market, the actual life cycle of the project is estimated to reach at least 20 years without significant additional investment costs, which would lead to an NVP of EUR 55 million, and an IRR of $12.5 \%$ year. With the financial indicators at limit, authors considered that a sensitivity analysis is needed. The annual cost of Power and Energy Losses is highly dependent on the electricity market price and the sensitivity of NPV with this price is shown in fig. 2 . Revenues are highly dependent on the transmission tariff that is approved by ANRE-the Romanian Energy Regulatory Authority and has the sharpest gradient in fig. 2.

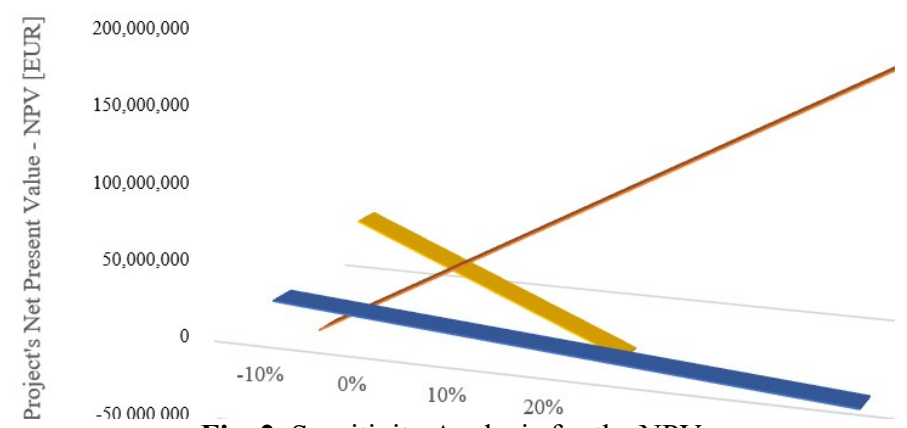

Fig. 2. Sensitivity Analysis for the NPV

\section{Conclusions and further research}

As presented in section 3, the equipment of the transmission network occupies around $210,000 \mathrm{~m}^{2}$ of valuable land, meaning $0.1 \%$ of the surface occupied by the city of Bucharest. The authors of this paper propose and analyse a bold idea, the refurbishing of the transmission network supplying the electricity for approx. 2 million inhabitants.

State of the art equipment with GIS for substations and XLPE cables for the connection lines are included in this analysis. This development comes in conjunction with the strategy of Transelectrica that has as one of the objectives to build a new HV substation in the city centre, with the same technology.

From a technical point of view, the implementation of GIS technology for substations has no disadvantages and leaves a lot of space for other needs. The installation of cables for the connection between substations will increase the value of the short-circuit currents but the circuit breakers in GIS bays will cope with it. The replacement of the OHLs with cables will require compensation coils for the reactive power.

Regarding the environmental impact, the technological change in the transmission network supplying the city of Bucharest will bring: A reduction with almost $90 \%$ of land surface occupied with the installations and related constructions, the almost complete elimination of the soil pollution threat, e.g. with mineral oil; only the power transformers will remain with mineral oil insulation, but the solution used for their foundation helps avoiding soil pollution in case of incidents and an improvement in the visual impact of the electrical network; GIS can be installed in buildings.

As further research on the development of the transmission network for supplying the city of Bucharest, authors will analyse the compatibility of such refurbishment with other utility networks. 


\section{References}

1. Vito Albino, Umberto Berardi and Rosa Maria Dangelico, "Smart Cities: Definitions, Dimensions, Performance, and Initiatives," Journal of Urban Technology, 2015, Vol. 22, No. 1, 3 - 21, http://dx.doi.org/10.1080/10630732.2014.942092.

2. https://www.unfpa.org/ [accessed in January 2020].

3. https://ec.europa.eu/eurostat/databrowser/view/tps00001/default/table?lang=en [accessed in January 2020].

4. https://ec.europa.eu/eurostat/statisticsexplained/index.php?title=File:Distribution_of_population_,_2011__o25,_V2.png [accessed in January 2020].

5. https://ec.europa.eu/eurostat/statistics-explained/index.php/Archive:Urbanrural_typology_update [accessed in January 2020].

6. https://www.iea.org/news/cities-are-at-the-frontline-of-the-energy-transition [accessed in February 2020].

7. European Environment Agency, "The European environment - state and outlook 2020 Knowledge for transition to a sustainable Europe," 2019.

8. National Statistics Institute, "Population by residence on $1^{\text {st }}$ of January 2019," http://www.insse.ro, Bucharest, 2019.

9. East Park, „Easy Park Group,” 2017. Available at: https://www.easyparkgroup.com/smart-cities-index/.

10. „Copenhagen Smart City”, Smart City Report, 2015.

11. Durable Urban Mobility Plan for București - Ilfov in the 2016-2030 perspective, http://www.pmud.ro/etapele-proiectului.html.

12. Power Transmission Network Development Plan in 2018-2027 perspective, CNTEE Transelectrica SA.

13. http://www.transelectrica.ro/web/tel/consum [accessed in December 2019]

14. Nicolae Golovanov, Gheorghe Comanescu, Mircea Scripcariu and Ioan Sevastian Bitir-Istrate, "Directions and Costs for reducing the environmental impact of refurbishing overhead lines and high voltage substations of the power transmission network, in accordance with the national and European legislation," Romanian Energy and Environment Foundation, University POLITEHNICA of Bucharest, 2004.

15. https://lege5.ro/Gratuit/gqydimjugq/inventarul-bunurilor-din-domeniul-public-mijloace-fixeconcesionate-cntee-transelectrica-sa-hotarare-684-2014?dp=gy4dgojxhazds [accessed in February 2020].

16. *** NTE $003 / 04 / 00$ "Technical norm for building overhead lines with rated voltages of over $1,000 \mathrm{~V}, " 2000$.

17. Laruelle, Elodie \& Kieffel, Yannick \& Ficheux, Arnaud, "g3-The Alternative to $\mathrm{SF}_{6}$ for HighVoltage Equipment." Lecture Notes in Electrical Engineering, pp. 139-146, 2018, doi:10.1007/978-3-319-58172-9_15.

18. Kieffel, Yannick \& Biquez, François \& Vigouroux, Daniel \& Ponchon, Philippe \& Schlernitzauer, Audrey \& Magous, Richard \& Cros, Gérard \& Owens, John, "Characteristics of g3 - an alternative to $\mathrm{SF}_{6}$, , CIRED - Open Access Proceedings Journal, pp 54-57, 2017, doi:10.1049/oap-cired.2017.0795.

19. https://www.gegridsolutions.com/press/gepress/sf6-free.htm [accessed in March 2020]

20. Romanian Parliament, "Government Decision no. 2139 from 30 November 2004 for approving the Normal Use Time and Classification of Capital Goods," 2004.

21. *** PE 134/95. "Technical norms for determining short-circuit currents in power grids with rated voltages of over $1.000 \mathrm{~V}, " 1995$.

22. CNTEE Transelectrica SA, 2014. [Interactiv]. Available: http://www.transelectrica.ro/web/tel/emisiune-de-obligatiuni. [accessed in March 2020].

23. Romanian Energy Regulatory Agency - A.N.R.E., "Key Performance Indicators and Technical State of the Power Transport and Distribution Networks and System Services," 2018. https://www.anre.ro/ro/energie-electrica/rapoarte/rapoarte-indicatori-performanta [accessed in December 2019] 